\title{
Relato de experiência com a Khan Academy em um curso técnico à distância
}

\author{
Raquel Machado Leite ${ }^{1}$, Vanessa Ribas Fialho ${ }^{2}$ \\ ${ }^{1}$ Centro de Ciências Computacionais - Universidade Federal do Rio (FURG) \\ Caixa Postal 474 - 96.201-900 - Rio Grande, RS - Brazil \\ ${ }^{2}$ Centro de Artes e Letras - Universidade Federal de Santa Maria (UFSM) - Santa \\ Maria, RS - Brazil \\ tpraquel@gmail.com, vanessafialho@gmail.com
}

\begin{abstract}
This work presents the Khan Academy educational platform and qualitatively analyzes its exploration through the students of the Technical Course in Didactic Multimedia offered at a distance by a public institution of education, within the scope of the discipline Applied to Education. The method is based on qualitative research through data collection. It was tried to show that educational institutions, even in circumstances of contingency of material and financial resources, are able to explore ideas and test hypotheses through the computational tools.
\end{abstract}

Resumo. Este trabalho apresenta a plataforma educacional Khan Academy e analisa qualitativamente sua exploração por meio dos alunos do Curso Técnico em Multimeios Didáticos ofertado à distância por uma instituição pública de ensino, no âmbito da disciplina Informática Aplicada à Educação. $O$ método parte da pesquisa qualitativa por meio de levantamento de dados. Intentou-se evidenciar que os estabelecimentos de ensino, mesmo em circunstâncias de contingência de recursos materiais e financeiros, são capazes de explorar ideias e testar hipóteses por intermédio dos instrumentos computacionais.

\section{Introdução}

O espaço educacional continuamente atua como agente do progresso social, dessa forma, nada mais proveitoso que utilizá-lo transformando o ato de construção do conhecimento em uma tarefa prazerosa por meio de artifícios e caminhos que se empenhem em evidenciar sentidos e motivações para a construção de um sujeito instruído para as exigências contemporâneas.

Nesse sentido Maciel et al. (2012) fazem referência ao espaço escolar afirmando que ele:

[...] Continua sendo um espaço privilegiado para o conhecimento e intervenções sobre os fenômenos complexos necessários para a convivência e a mudança social. É por isso que o ingresso das TIC's nas escolas se vincula 
com a alfabetização nas novas linguagens, onde se obtêm novos saberes e a habilitação para novas demandas do mercado de trabalho.

$\mathrm{Na}$ intenção de colaborar junto a esse processo, este trabalho objetiva explorar qualitativamente a Plataforma Educacional Khan Academy, por meio de uma tarefa proposta aos alunos no âmbito da disciplina Informática Aplicada à Educação, Curso Técnico em Multimeios Didáticos, ofertado à distância por uma instituição pública de ensino.

Justifica-se a escolha da Kahn Academy por ser uma ferramenta online, aberta, gratuita, sem limite de usuários e de utilização, contemplando a dinâmica vigente da sociedade da informação, por se apresentar como um mecanismo tecnológico com vasto potencial para ser empregado nos espaços educacionais do século XXI.

Segundo a Fundação Lemman" "é o maior site de matemática do mundo", atualmente oferecendo mais de 300 mil exercícios interativos divididos em: matemática por assunto, matemática por ano, ciências, engenharia, economia, finanças, computação, artes e humanidades. Segundo seus administradores "é um recurso para todas as idades, oferecendo exercícios, vídeos de instrução e um painel de aprendizado personalizado que habilita os estudantes a aprender no seu próprio ritmo dentro e fora da sala de aula".

Todos os membros da rede, ao efetuar login, criam um perfil com nome de usuário, avatar, biografia e localização. Através deste podem interagir com outras pessoas que utilizam a plataforma, formando assim, uma grande rede social educacional, pois de acordo com Marteleto (2001, p.72), as redes sociais são formadas por "um conjunto de participantes autônomos, unindo ideias e recursos em torno de valores e interesses compartilhados".

O método parte da pesquisa bibliográfica, explorando materiais disponibilizados nos repositórios digitais e da investigação qualitativa por meio de levantamento de dados para análise.

O trabalho está organizado em quatro seções, a primeira traz a introdução, a segunda aborda os métodos aplicados para a catalogação dos dados, na seção três são especificados os resultados e na quarta são divulgadas as conclusões do estudo originário da tarefa didática proposta aos alunos do Curso Técnico em Multimeios Didáticos, no contexto da disciplina Informática Aplicada à Educação.

\section{Métodos}

Para a escrita desse artigo foi realizada uma pesquisa qualitativa, que segundo Gil (2008), pode envolver levantamento bibliográfico e entrevistas com pessoas experientes, além da coleta de dados através de questionário e observação sistemática sobre o problema pesquisado. Para Bogdan e Biklen (1994), o viés qualitativo tende a pesquisar fenômenos propostos em toda sua complexidade e contexto natural. Também conforme Bogdan e Biklen (1994, p. 48), a investigação qualitativa é basicamente descritiva, ou

\footnotetext{
${ }^{1}$ http://www.fundacaolemann.org.br/khan-academy/ - organização sem fins lucrativos - parceira da Khan Academy no Brasil, traduz para a língua portuguesa os materiais disponibilizados em outros idiomas.

${ }^{2}$ https://pt.khanacademy.org/about
} 
seja, "os resultados escritos da investigação contêm citações feitas com base nos dados para ilustrar e substanciar a apresentação".

Para a realização da análise qualitativa foi proposta uma atividade online no ambiente de aprendizagem Moodle para todos os alunos matriculados na disciplina Informática Aplicada à Educação, do Curso Técnico em Multimeios Didáticos, ofertado à distância por uma instituição pública de ensino, nos Polos A, B e C.

Os discentes, após lerem as orientações de uso através dos materiais disponibilizados, acessaram a página da Khan Academy, acederam o perfil Alunos, comecem por aqui, realizaram o cadastro através da conta do Facebook ou Gmail, exploraram os materiais disponíveis e testaram a ferramenta.

Ao final da experimentação responderam duas questões:

a) Como foi sua experiência com a Khan Academy?

b) Como você faria a proposta de utilização?

A tarefa ficou aberta para execução e envio das respostas durante duas semanas, no período de 27 de março a 09 de abril de 2017 e foi respondida por 12 alunos de um total de 20, distribuídos em três polos de apoio presenciais. O curso inicialmente contava com 95 matriculados. Atualmente, devido à evasão, os participantes que efetivamente entregam as tarefas propostas são contabilizados em até 20.

É muito importante enfatizar que esta atividade não intencionou analisar a capacidade técnica dos discentes na utilização do ambiente educacional, por isso as questões não levaram em conta as habilidades iniciais no uso da ferramenta. $\mathrm{O}$ maior propósito foi apresentar uma alternativa de ambiente de criação que utiliza os recursos computacionais no processo educacional.

Posteriormente à aplicação da tarefa, foi realizado o levantamento de dados que produziram resultados de forma qualitativa. Silveira e Córdova $(2009$, p.31) descrevem que esta análise "não se preocupa com representatividade numérica, mas, sim, com o aprofundamento da compreensão de um grupo social, de uma organização, etc".

\section{Resultados}

A análise dos dados foi realizada após a correção e interpretação das respostas enviadas pelo ambiente virtual de aprendizagem Moodle. Nos Polos A e B apenas um educando realizou a tarefa, portanto se obteve somente uma resposta em cada local. Dos alunos do Polo C, dez respostas foram auferidas, sendo o atual Polo com maior número de alunos cursantes.

Das doze respostas enviadas, apenas uma, do Polo $\mathrm{C}$, descreveu a Khan Academy como satisfatória em parte, até se contradizendo em determinado momento, pois conclui que gostou da ferramenta, entretanto considerou incompleta a tradução dos materiais da língua inglesa para a língua portuguesa, quando, na realidade, a tradução é 
VI Congresso Brasileiro de Informática na Educação (CBIE 2017)

Anais do XXIII Workshop de Informática na Escola (WIE 2017)

feita de forma simultânea através de legenda pela página de compartilhamento de vídeos $Y_{\text {YouTube }}{ }^{3}$, configurando uma ponderação não fidedigna.

Todos os pontos de vista serão identificados pelas iniciais do nome do aluno. As redações foram revisadas e adaptadas para uma melhor compreensão textual. Seguem os comentários.

\title{
a) Como foi sua experiência com a Khan Academy?
}

\begin{abstract}
"Minha experiência foi satisfatória, educação gratuita, onde com o uso da tecnologia é possível o acesso ilimitado a conteúdos escolares, abrangendo qualquer faixa etária, mostrando que a educação formal tem que mudar, ficando mais alinhada com as mudanças que vem ocorrendo, já que o mundo requer um processamento de informação mais ativo. Gostei onde Khan diz: 'que seu método quebra a passividade na sala de aula, incentivando a interação entre alunos e professores, e respeitando o ritmo de cada aluno no processo de aprendizagem'. Isso faz com que o tempo de assimilação dos conteúdos, diferente para cada pessoa, seja respeitado. Gostei de alguns vídeos, são ótimos, assisti sobre 'asma', muito bem explicado, inclusive a anatomia da árvore respiratória”. (J.J.C.L.M.)
\end{abstract}

\section{b) Como você faria a proposta de utilização?}

"Para o uso dessa tecnologia seria necessário expor a utilidade do programa, onde deverá haver muito estudo, atendendo as particularidades da escola, e o currículo a ser respeitado. Então é necessário um periodo de adaptação onde as dificuldades são: a tradução dos vídeos, a adequação para o currículo da escola, lembrando que ainda temos alunos sem acesso às tecnologias para o uso da metodologia. Em conversa com os colegas de trabalho, eles nunca tiveram contato com a 'Khan Academy', comentei que há vídeos de diversas matérias, como Matemática, Química, Economia, Ciências..., que os alunos podem ter acesso a essas matérias e seus conteúdos fora do horário escolar, escolhendo o ambiente e horário. Não houve boa aceitação, até por que ainda tem vários vídeos, que não foram traduzidos". (J.J.C.L.M.)

O feedback do professor para essa argumentação foi a orientação de como ativar e desativar a legenda no YouTube, por meio de um tutorial ${ }^{4}$ disponível no próprio site, bem como, quanto à aceitação dos docentes, para uma alegação mais conclusiva, o correto seria a exploração da ferramenta e que, a partir daí, ocorra a decisão do quanto pode ser útil (ou não) no trabalho em sala de aula. Observa-se que apesar de não considerar uma solução plenamente eficaz, a aluna intentou replicar o conhecimento, comentando com os colegas professores a existência da plataforma educacional.

As outras onze considerações foram tão somente positivas, nenhum aluno possuía conhecimento da existência da plataforma, contemplando a ideia inicial do trabalho, que era de apresentar um mecanismo computacional acessível, gratuito e com

\footnotetext{
${ }^{3} \mathrm{https}: / /$ www.youtube.com/

${ }^{4}$ https://support.google.com/youtube/answer/100078?co=GENIE.Platform\%3DDesktop\&hl=pt-BR
} 
VI Congresso Brasileiro de Informática na Educação (CBIE 2017)

Anais do XXIII Workshop de Informática na Escola (WIE 2017)

potencial educacional. As respostas convergem para uma ferramenta prática e de fácil utilização, satisfazendo a proposta de emprego como método didático.

As ponderações consideradas mais pertinentes são descritas a seguir, como forma de trazer maior consistência para esse trabalho de análise qualitativa.

No primeiro bloco de citações estão as respostas da questão "como foi sua experiência com a Khan Academy?".

"Ao explorar a plataforma fiz uma viagem no tempo, me imaginei de novo em sala de aula a quarenta anos passados em uma escola em que as professoras não possuíam esta ferramenta extraordinária para ensinar, apenas o quadro negro, o giz e a competência da educadora para transmitir conhecimentos e a boa vontade do aluno em aprender". (M.R.L.E)

"Para acessar foi fácil, fiz o acesso pelo login do facebook, não conhecia o site e achei muito interessante e proveitosa a proposta de estudo de Matemática, Química, Física e Biologia. Foge dos padrões corriqueiros das aulas tradicionais e pode ser utilizado por pessoas em qualquer faixa de aprendizagem. $O$ incentivo que faz parte de cada questão respondida faz com que o aluno queira buscar mais conhecimento". (R.M.B.)

"Este site é maravilhoso, já vou sugerir para as professoras da escola. Abrange todas as áreas de ensino de uma forma lúdica. Escolhi a opção adição e subtração, mas confesso que se tivesse tempo acessaria todos eles". (R.B.R)

"Minha experiência foi muito interessante, tentei experimentar tanto assuntos básicos que tenho conhecimento, como matemática para os primeiros anos como assuntos mais avançados, como cálculo, saúde e medicina. Achei muito interessante a abordagem de primeiro ensinar através de um vídeo explicativo, que na maioria das vezes é bem didático, e depois dar a possibilidade de praticar a respeito do assunto.

O fato de dar pontos ao acertar as respostas, gerando energia, é bem motivador para os alunos pequenos. Muitas partes estão em inglês, o que pode gerar um certo receio a princípio, mas como todos os vídeos possuem tradução, esse problema passa a ser secundário e tudo pode ser entendido perfeitamente". (N.R.J.)

"Achei realmente muito interessante, tive dificuldade para conseguir acessar, depois consegui, achei muito bom poder estudar vários assuntos como artes, humanidades, microeconomia, macroeconomia, ciências, engenharia, matemática. Mas o que mais me chamou a atenção foi o tema empreendedorismo, visto que o nosso projeto para o ano de 2017, entre outros temas, foca justamente nisto, então assisti ao vídeo com Reid Hoffman, consegui colocar a legenda e foi bastante produtivo poder escutá-lo, falou sobre sua trajetória estudantil e que aos doze, treze anos, já sabia que a partir do sétimo ano já seria responsável por si mesmo, então despertou em mim que devo passar para minhas crianças que ser um pequeno empreendedor é desde pequeno ter essa consciência de interesse pelos estudos, pelas novas descobertas, pelo comprometimento". (R.M.P.)

Podemos considerar nas falas dos participantes as reflexões quanto à práxis antiga $x$ contemporânea e a intenção do saber compartilhado, aprendendo para si e 
VI Congresso Brasileiro de Informática na Educação (CBIE 2017)

Anais do XXIII Workshop de Informática na Escola (WIE 2017)

também para dividir com os outros. No segundo bloco de citações estão as considerações para a questão "como você faria a proposta de utilização?"

\section{Os comentários mais relevantes se encontram dispostos na sequência.}

"Utilizaria essa ferramenta como um auxilio tanto para os alunos quanto para os professores, complementando o aprendizado e até mesmo para o debate em sala de aula, do que os alunos encontraram de mais interessante neste ambiente, implementando aos poucos a arte digital e seus segmentos no dia a dia da sala de aula". (B.G.S.)

"Acredito que seria interessante cada aluno da escola ter seu cadastro no site, no qual poderão assistir os vídeos e realizar as atividades, e o professor sendo o mediador nesse processo. $O$ uso nas aulas tornaria possível trabalhar conteúdos do planejamento de forma lúdica, tornando o ensino mais prático e vivencial, com mais experimentações, informações, conhecimentos, com isso dando mais significado ao que se ensina e se aprende, e possibilita que o aluno concretize o conteúdo e possa estabelecer relação entre a teoria e a prática. Tornaria o aluno mais motivado a buscar resultados, a resolver os problemas propostos, pois muitas vezes em uma aula expositiva em sala de aula o conteúdo se torna chato e sem atrativos ao aluno”. (D.M.S.)

"Primeiro iria estudar como funciona bem o site, aprender a trabalhar com ele para poder acompanhar os alunos, colocaria essa proposta para equipe diretiva, e após aprovado pela Supervisora Escolar, conforme os conteúdos que estão sendo desenvolvido no Plano Curricular da Escola, levaria os alunos até o Laboratório de Informática para que os mesmos pudessem ter acesso ao site e começassem a assistir os vídeos e desenvolver as atividades propostas.

Essa atividade só irá expandir o aprendizado dos alunos desenvolvendo o seu raciocínio lógico, sanando as suas dificuldades e fazendo com que os mesmos comecem a avançar cada dia mais no seu aprendizado com prazer. O meu papel seria de auxiliá-los nas dúvidas e dificuldades que cada um apresentasse individualmente”. (E.T.R.L.)

"Minha proposta para a utilização seria determinar o assunto a ser considerado, como na parte de geometria, por exemplo. Mostrar em sala um vídeo inicial que está na Khan Academy com a história do assunto (visto que a maioria dos assuntos do site possui um pouco da história a respeito do mesmo) e depois faria a aula explicando os conceitos e dando exemplos. Após levaria os alunos para a sala de informática para que cada um abrisse o site e buscasse o assunto estudado para praticar os exercícios e assistir os vídeos, caso ainda tenham dúvida. O professor acompanharia o desenvolvimento de cada um”. (N.R.J)

"Este site poderia ser utilizado como uma extensão da sala de aula, para o tema de casa, onde o professor pode cadastrar seus alunos e acompanhar as atividades que estes realizam, em caso de estudantes que não possuem computador e acesso à internet em suas casas pode-se disponibilizar no laboratório de informática da escola". (R.M.B)

"Se tivesse laboratório de informática na escola sugeriria fazer o cadastro de todos os alunos e de acordo com a disciplina organizar um cronograma duas vezes por semana, de uns 40 minutos para o aluno acessar a Khan Academy. Depois faria uma provinha com exercícios copiados dele para verificar o grau de aprendizagem de cada aluno". (R.B.R.) 
Analisando as argumentações de forma geral, se percebe que não houveram grandes problemas para apropriação da ferramenta, nota-se um grande interesse em usufruir do instrumento computacional como método didático e compartilhar a existência da ferramenta, o que já suscita e motiva um distanciamento de aulas expositivas tradicionais.

\section{Conclusões}

As reflexões descritas por alguns alunos, associando teoria à prática educativa, tanto individual como coletiva, já proporcionaram sentido a este trabalho, pois o objetivo principal de propagandear uma ferramenta que promova o pensar para o discernimento e a perspectiva sobre a evolução das tecnologias x metodologias, evocando qual o papel do profissional da educação como ativista e participante para transformar a realidade em que está inserido, foi concluído com êxito.

Além do elemento pedagógico, a interface da plataforma foi considerada amigável e a navegação intuitiva, os novos usuários não encontraram grandes dificuldades de acesso, portanto é uma ferramenta que pode ser recomendada até mesmo para indivíduos com nível básico de conhecimento computacional.

Para contribuir e apoiar na disseminação da ferramenta, a Plataforma de cursos online gratuitos Coursera ${ }^{5}$ oportuniza a formação "Explorando os recursos educacionais da Khan Academy", no qual qualquer pessoa com interesse em saber mais sobre o recurso pode criar uma conta e participar.

Os resultados demonstram que, mesmo com poucos recursos, existe a possibilidade de conceber um aluno mais estimulado, atraído, livre para implementar ideias e realizar uma conexão entre organização do conhecimento, pessoas, lugares e tecnologias.

Os meios computacionais aqui demonstrados são gratuitos e livres, não demandando grandes investimentos em infraestrutura, cabendo à comunidade escolar apenas disposição para sair da zona de conforto e se apropriar dos ambientes como espaços criativos, colaborativos e de interações sociais.

\section{References}

Bogdan, R. e Biklen, S. (1994). "Características da investigação qualitative”. In: Investigação qualitativa em educação: uma introdução à teoria e aos métodos. Porto: Porto Editora, p.47- 51.

Gil, A. (2009). "Como elaborar projetos de pesquisa". http://wp.ufpel.edu.br/ecb/files/2009/09/Tipos-de-Pesquisa.pdf4, abril.

Maciel, M., Leite, R. e Passerino, L. (2012). "Cinco anos de Ceibal: a inclusão digital e suas mudanças nas comunidades fronteiriças”. Anais do XVIII WIE, Rio de Janeiro.

\footnotetext{
${ }^{5}$ https://pt.coursera.org/

${ }^{6} \mathrm{https}: / /$ pt.coursera.org/learn/khanacademy
} 
VI Congresso Brasileiro de Informática na Educação (CBIE 2017)

Anais do XXIII Workshop de Informática na Escola (WIE 2017)

Marteleto, R. (2001). “Análise de redes sociais: aplicação nos estudos de transferência da informação". Ciência da Informação, Brasília, v. 30, n. 1, p. 71-81.

Silveira, D. e Córdova, F. (2009). "A Pesquisa científica". http://www.ufrgs.br/cursopgdr/downloadsSerie/derad005.pdf, março. 